\title{
Philosophy in Chinese and Western Traditional Garden Landscape
}

\author{
Qian Shi \\ School of Fine Art and Design, \\ Kunming University, \\ Kunming, Yunnan, 650214
}

\author{
Yang Ping \\ School of Foreign Language, \\ Kunming University, \\ Kunming, Yunnan, 650214
}

\begin{abstract}
Philosophy is a theoretical and systematic world view. As the generalization and summary of people's natural knowledge, social knowledge and thinking knowledge. Philosophy, is the unity of world view and methodology. It is the concre te exis tence and manifestation of social consciousness and a social science with philosophical world outlook and methodology as its content. [1] The differences in social ideologies be tween China and the west lead to different philosophical ideas. The difference of philosophical thoughts leads to the difference of aesthe tic forms. As a whole, we can see the different philosophical wisdom of the ancient people in both Chinese and western classical gardens, whether in the Chinese gardens of Suzhou or the palace of Versailles in the west. The study of Chinese and western classical philosophy can help us better understand the differences between Chinese and western gardens, and can guide our modern design.
\end{abstract}

Keywords-Chinese and western philosophy; Traditional garden landscape; Aesthetic performance

\section{CHINESE CLASSICAL GARDEN}

\section{A. Ancient Chinese philosophy in Chinese classical gardens}

Chinese classical gardens originated from Zhou and Han dynasties and developed in Wei, Jin and southern and northern dynasties. It is mature in Sui, Tang, five dynasties, Ming and Qing dynasty is the climax of the development of Chinese classical gardens. Chinese classical garden is not only the carrier of Chinese culture but also the world's valuable heritage. Most Chinese classical gardens were built by literati. During the process of their construction, literati and literati would inevitably integrate their understanding of traditional philosophy into their gardening. Therefore, the study of Chinese classical gardens must start with Chinese traditional philosophy.

\section{1) Ancient Chinese philosophy}

Ancient Chinese philosophy originated from Confucianism, Taoism and Buddhism. An important characteristic of Confucianism is 'benevolence, righteousness, propriety, wisdom and faith". Taoism advocates " For I am abstracted from the world, the world from nature, nature from the way, and the way from what is beneath abstraction." ; Buddhism is a foreign culture, but after thousands of years of integration, has taken a strong national color. The three schools of thought are different but consistent. They are interdependent

Research Fund Project of Humanities and Social Sciences of Kunming University: "Application and Exploration of Architectural Decoration Patterns of the Bai Nationality Traditional Residence in Dali in Modern Landscape Design" (No.XJW15012) relationships. In the long history of the long river, China has gradually formed a distinctive Chinese philosophy. In classical Chinese philosophy, people believe that man and nature are one. Nature is our teacher. We should learn from nature. Chinese classical philosophy advocates romantic and elegant demeanor and unadorned temperament and sentiment, and opposes extravagance and waste. These shape quietly elegant literati feelings. This simple philosophy has influenced the aesthetics of ancient China as well as the garden art.

\section{2) Philosophical thoughts of Chinese classical gardens}

In the construction process of Chinese classical gardens, neither street trees, hedges or flower beds are regulated. This is precisely following Lao-tzu's philosophy of 'the way from what is beneath abstraction”. Although Chinese classical gardens are artificial, they are just like natural ones. The method of planting and stone placement is completely in accordance with the distribution pattern of nature. The laws of human and nature are consistent. We think of nature as a human teacher and we are only a part of nature. People need to regulate their behavior according to the laws of the universe. This philosophy has always guided ancient people's way of thinking and behavior, which has permeated every aspect of ancient Chinese culture in the long years.

\section{WESTERN CLASSICAL GARDEN}

\section{A. western classical philosophy}

Western philosophy developed from the ancient Greek ontology. In modern western philosophy, epistemology was the main philosophy. Its basic idea is the subjective and objective dichotomy. [2] Western culture emphasizes the use of things and the conquest of nature. From the point of view of the development history of philosophy, there have been two schools of materialism and idealism in the west. But whichever faction has the upper hand; all emphasize the role of rational cognition in practice. Under the influence of this social consciousness, aesthetics will naturally be built on the basis of "rational aesthetics". German idealist philosopher Hegel once said to aesthetics that 'beauty is the perceptual manifestation of ideas". Michelangelo said that "the real object of art is the human body". Many western artists, such as Leonardo Da Vinci and Durer, are obsessed with studying the proportion of human body, trying to find the essence of beauty and express it through rational mathematical formulas. [3] Western artists try to find beauty factors in terms of quantity and relationship. The 
famous "golden section" was put forward by the Pythagorean school in the 6th century Cathey strongly adjust one, order, order and uniform and balance symmetry, advocating geometric graphics. They try to set the standard of beauty in a normalized pattern. This idea has influenced European sculpture, painting, music, drama and architecture as well as gardens.

\section{B. philosophical thoughts of western classical gardens}

The philosophy of human-centered and rational understanding and treatment of nature has been influencing western gardens. They lay particular stress on artificial processing and transform the garden according to human's will. They embody the beauty of artificiality and reason. For example, France's palace of Versailles, Fontainebleau palace; Hampton court palace, England; Berlin palace garden; Hecht Lorong gardens, Holland, et celebrates are the outstanding representatives of western classical gardens which embody this philosophy. In 1638, in on gardening art, baiaos of France proposed that "the most perfect thing that can be found is defective if not organized and organized". Obviously, the western garden art embodies the physical, numerical and abstract regularity of a scientific skill. This regularity, however, is hard to find in nature. They pay attention to the construction of geometric patterns, in the plane, three-dimensional geometry. All scenes and objects are regular and regular, reflecting the relationship of precise mathematical theory, and pursuing the beauty of artificial. [4]

\section{COMPARISON OF CHINESE AND WESTERN CLASSICAL GARDEN ART PERFORMANCE DIFFERENCES}

There are obvious differences in artistic expression between Chinese and western gardens. The differences in philosophy lead to the differences in the forms of expression between Chinese and western classical garden aesthetics. In the west, uniformity and symmetry are emphasized. The works designed in the west have obvious axial symmetry, stress on the organization of several patterns, and even the flowers and trees in nature are cut into geometric shapes, all of which are restrained to reflect a kind of artificial beauty. Chinese characteristics come from nature, but higher than nature, and pay attention to the ingenious combination of artificial beauty and natural beauty.

\section{A. Architecture of Chinese and western classical gardens}

The status of garden architecture in Chinese and western classical gardens is totally different. Most western buildings have complex functional Spaces within a single building. Most of Chinese traditional buildings have different functions. The monomer of Chinese style architecture is mostly rectangular, which is a scattered layout. The buildings in the garden are often hidden in mountains, rocks and jungles. Architecture became a part of nature; nature became a part of architecture. This implicit expression best reflects the combination of artificial beauty and natural beauty. Human and nature are equal, and it reflects the identity of people's life demands and spiritual enjoyment everywhere.
Although western garden architecture has formed different architectural styles in history, it has not changed as the main part in the whole garden. The western architectures are mostly brick and stone walls, and the buildings pursue the beauty of artificial. The monomer volume of western buildings is generally large, and the building contains almost all required functional Spaces. The building facade porch, window arch and mountain flowers are mostly arranged by geometrical principles. The exquisite sculpture or gorgeous pattern adheres to the surface of the building, all of which demonstrates human wisdom and strength. The beauty of artificial and rational is embodied incisively and vividly in western architecture.

\section{B. The application of water in Chinese and western classical gardens}

In the application of water in gardens, the water in Chinese gardens imitates the water in natural forms. Water in a garden is usually in no particular form. The revetment is mostly piled with rocks without clear demarcation line. The meandering and zigzagging of water body include both zonal water body and facial water body, as well as wide and narrow water body, stream body, stream body and pool body. Such a form makes people completely unable to feel it is artificial water body. The artistic treatment of water in Chinese gardens is a combination of static and static, that is, static and static. On the surface of ponds and lakes, flowers, fish and boats can be raised, forming dynamic landscape on the water surface. The water surface is combined with Bridges, dikes, pavilions and plants to form a beautiful lyric picture. [5]

The water in western gardens is mostly geometric and regular pools, canals, springs and fountains. Water and sculpture are combined to form a variety of water column modeling by fountain, with lamp post modeling and lamplight change come rich water column color, reflecting technical glamour. [6]

\section{C. arrangement of flowers and trees in Chinese and western classical gardens}

In China, flowers and trees are an indispensable design element for gardens. Chinese garden is not only a visual art, but also involves hearing, smell and other organs, and the change of climate throughout the year will also affect human feelings. [7] These factors often work with the help of flowers and trees. The planting ways of Chinese gardens are complex and varied, including solitary planting and cluster planting. Solitary plants are used to adorn the space as the main scene, and cluster plants are used to set off the building. The rich levels bring out the best in architecture and nature. Different plants can express different feelings in different courtyards. There are plantains in the corner of yuan garden. It uses the sound of the rain beating down on plantains to render the rain scene. Moreover, the theme of appreciating pines and cypresses is "Winnington wind", and the theme of "looking at pines and reading paintings" in the net master garden all use plants to express the gardeners' unique feelings about the worship of nature.

Western and Chinese philosophy and aesthetic concepts are different. They pay more attention to the design of flower bed, often use low shrubs or flowers and leaves and beautiful plants. 
Such expression gives exquisite design, adornment pattern and water scene collocation are like gorgeous carpet. Since ancient Rome, the west has paid attention to the use of forms in garden plants. In the early days, they would trim hedges with leafy, germinating plants. Later, they often cut plants into geometric shapes, words and patterns, and even the shapes of animals and characters, giving people a sense of grandeur.

\section{CONCLUSION}

Due to the differences in philosophical thoughts, Chinese and western aesthetic concepts are also different. They also have different views on architecture and nature. Chinese classical garden advocates nature and regards nature as its teacher. It believes that human beings are equal to nature and pursues the aesthetic realm of "harmony between nature and human”. Western classical gardens embody the philosophy of human-centered, rational understanding and treatment of nature, and create a precise and regular pattern construction. [8] Although Chinese and western classical gardens have different forms of expression, they are neither superior nor inferior. Together they constitute a rich and colorful world garden.

\section{REFERENCE}

[1] Miao Changsheng. Fengshui is a Comprehensive Discipline of Social Science and Natural Science, and its Effect on People is Actually the Field Energy Effect of Dark Matter [J] Yi-ology and Architecture Culture High Level Forum, 2009

[2] Shan Ling. Embodiment of Chinese and Western Philosophical Thoughts in Classical Gardens. [J]. Cultural and Educational Materials. 2010.11

[3] Chen An. Roof Greening --- A Way to Explore New Green Space [J]. Chongqing University of Architecture, Chongqing, 1999.

[4] He Chengyi. A Comparative Study on the Time-space of Landscape Architecture in Western Sichuan in Different Historical Periods [J]. Chengdu University of Technology.2016.

[5] Ouyang Jianqiu. A Brief Analysis of the Influence of Chinese and Western Philosophical Thoughts on Traditional Gardens [J]. Shanxi Architecture.2008.

[6] Bian Songlei. Study on Metaphorical Design Based on Garden Space [J]. Central South University for Nationalities, 2014. 